\title{
Trypanosoma rangeli protein tyrosine phosphatase is associated with the parasite's flagellum
}

\author{
Elisa Beatriz Prestes ${ }^{1}$, Ethel Bayer-Santos ${ }^{1}$, Patrícia Hermes Stoco ${ }^{1}$, Thaís Cristine Marques Sincero', \\ Glauber Wagner', Adriana Umaki², Stenio Perdigão Fragoso², Juliano Bordignon², \\ Mário Steindel' ${ }^{1}$ Edmundo Carlos Grisard ${ }^{1 /+}$
}

'Laboratórios de Protozoologia e de Bioinformática, Departamento de Microbiologia, Imunologia e Parasitologia, Centro de Ciências Biológicas, Universidade Federal de Santa Catarina, Florianópolis, SC, Brasil 'Instituto Carlos Chagas-Fiocruz, Curitiba, PR, Brasil

Protein tyrosine phosphatases (PTPs) play an essential role in the regulation of cell differentiation in pathogenic trypanosomatids. In this study, we describe a PTP expressed by the non-pathogenic protozoan Trypanosoma rangeli (TrPTP2). The gene for this PTP is orthologous to the T. brucei TbPTP1 and Trypanosoma cruzi (TcPTP2) genes. Cloning and expression of the $\operatorname{Tr} P T P 2$ and Tc PTP2 proteins allowed anti-PTP2 monoclonal antibodies to be generated in BALB/c mice. When expressed by $\mathrm{T}$. rangeli epimastigotes and trypomastigotes, native TrPTP2 is detected as a $\sim 55 \mathrm{kDa}$ protein associated with the parasite's flagellum. Given that the flagellum is an important structure for cell differentiation in trypanosomatids, the presence of a protein responsible for tyrosine dephosphorylation in the T. rangeli flagellum could represent an interesting mechanism of regulation in this structure.

Key words: Trypanosoma rangeli - protein tyrosine phosphatase - flagellum

Tyrosine phosphorylation is a key mechanism involved in cell regulation and differentiation. In kinetoplastid protozoans, such as trypanosomes, there is evidence that several proteins are phosphorylated on tyrosine residues (Andreeva \& Kutuzov 2008). Determination of the TriTryp phosphatome (Brenchley et al. 2007) revealed that the Trypanosoma cruzi, Trypanosoma brucei and Leishmania major protein tyrosine phosphatases (PTPs) comprise 2.3\%, 2.6\% and 3.4\% of the phosphatase complements of these organisms, respectively, in contrast to the $16 \%$ observed in humans. In addition, the significant difference between kinetoplastid PTPs and their human homolog (33\% amino acid identity) suggests a promising role for these enzymes as targets for therapeutic drugs (Brenchley et al. 2007).

Several phosphatases have been described in protozoans, suggesting their role in regulating the development of these organisms. T. brucei PTP (TbPTP1) is associated with the cytoskeleton and has been reported to be intrinsically involved in this parasite's life cycle (Szoor et al. 2006), as its inactivation through chemical and genetic methods triggered the differentiation of morphologies ranging from infective stumpy forms to non-infective procyclic forms. The downstream step in this developmental signalling pathway was determined to involve a DxDxT phosphatase found in T. brucei glycosomes (Szoor et al. 2010). Additionally, a T. cruzi PTP was recently purified and biochemically characterized

Financial support: CAPES, CNPq, FINEP

EBP nad EB-S contributed equally to this work.

+Corresponding author: edmundo.grisard@ufsc.br

Received 13 February 2012

Accepted 27 May 2012
(Gallo et al. 2011). Inhibition of this PTP using BZ3, a human PTP1b inhibitor, reduced the time required for the differentiation of epimastigotes to metacyclic forms and decreased the infectivity of trypomastigotes in L6 rat skeletal muscle cells by 50\% (Gallo et al. 2011).

Considering the importance of PTPs in pathogenic trypanosomes, the present study focuses on the description of a PTP in T. rangeli (TrPTP2), a non-pathogenic Latin American protozoan closely related to T. cruzi. T. rangeli strains are divided into two major lineages that differ in their ability to infect certain Rhodnius species (Vallejo et al. 2002). These lineages are designated $\mathrm{KP} 1(+)$ and KP1(-) based on the presence/absence of distinct types of kinetoplast DNA (kDNA) minicircles.

The life cycle of $T$. rangeli requires complex machinery to regulate cell differentiation, in which PTPs must play an important role. The first study on PTPs in T. rangeli showed that there are differences in tyrosine phosphatase activity between the long and short epimastigote forms (Gomes et al. 2006). The importance of this group of proteins for the T. rangeli life cycle was reaffirmed by the finding that inhibition of surface ectophosphatases impaired parasite proliferation (Fonsecade-Souza et al. 2009). Additionally, ecto-phosphatase activity appears to be modulated by hydrogen peroxide (Cosentino-Gomes et al. 2009), which may be produced by the parasite, as well as by the concentration of inorganic phosphates in the medium (Dick et al. 2010). Although these studies have evaluated total ecto-phosphatase activity, the inhibitors used suggest the presence of PTPs among the surface phosphatases.

The aim of this study was to characterize the $T$. rangeli PTP gene by assessing both its intra and interspecific variability and to comparatively evaluate the levels and sites of $\operatorname{Tr}$ PTP2 protein expression in different forms and strains of this parasite. 


\section{MATERIALS AND METHODS}

Parasites - The T. cruzi Y strain and 17 T. rangeli strains from different hosts and geographical origins were used in this study (Table). The epimastigote forms were cultivated by weekly passages at $27^{\circ} \mathrm{C}$ in liver infusion tryptose medium supplemented with $10 \%$ foetal bovine serum after a cyclic mouse-triatomine-mouse passage. $T$. rangeli trypomastigotes were obtained through in vitro differentiation (Koerich et al. 2002) and T. cruzi trypomastigotes were obtained from the supernatant of infected Vero cells (Eger-Mangrich et al. 2001).

Nucleic acid extraction and gene amplification - Total DNA and RNA were extracted (Sambrook \& Russell 2001) from the T. cruzi $\mathrm{Y}$ strain and 17 T. rangeli strains isolated from different hosts and geographical origins (Table). Different primer sets based on previously obtained T. rangeli cDNA sequences (Grisard et al. 2010) were designed for amplification and sequencing of the complete TrPTP2 coding region, as well as the 3' and 5' UTRs (Supplementary data).

Sequence assembly and phylogenetic analyses - The obtained amplification products were sequenced using the Megabace $1000^{\circledR}$ DNA Analysis System with the DYEnamic ET terminator kit (GE Healthcare, Uppsala, Sweden) according to the manufacturer's instructions. Clusters were assembled with the Phred/Phrap/Consed ${ }^{\circledR}$ package and aligned using CLUSTALW software. Sequences of T. cruzi (GenBank XM_816368), T. brucei (GenBank XM_817818.1), Trypanosoma vivax (TriTrypDB TvY486_1006690) and Trypanosoma congolense (TriTrypDB TcIL3000.10.5750) PTP genes were retrieved from the GenBank or TriTrypDB database for comparative analysis. To construct a phylogenetic tree, the sequences were analysed with bootstrapped maximum parsimony and neighbour-joining methods using complete deletion and the Kimura-2 parameters in MEGA software version 4.0.2. The predicted TrPTP2 protein sequence was analysed using InterPro.

Southern and northern blotting - Southern and northern blot analyses were performed according to standard protocols (Sambrook \& Russell 2001). A peroxidase-labelled probe was prepared using an 821 bp polymerase chain reaction fragment and the ECL Direct Nucleic Acid Labelling and Detection System (GE Healthcare).

Recombinant proteins and mass spectrometry (MS/ MS) analysis - Recombinant His-tagged TrPTP2 and Trypanosoma cruzi TcPTP2 were produced in Escherichia coli BL21(DE3) cells transformed with the $\mathrm{pET}-14 \mathrm{~b}$ vector (Novagen) containing the coding region from either $\operatorname{Tr} P T P 2$ from the $T$. rangeli Choachí strain or TcPTP2 from the T. cruzi Y strain. Expression was induced by treatment with $1 \mathrm{mM}$ IPTG (isopropyl- $\beta$-dthiogalactopyranoside) at $37^{\circ} \mathrm{C}$ for $3 \mathrm{~h}$ and the recombinant proteins were purified through electroelution $(4 \mathrm{~h}$ at $70 \mathrm{~V}$ ) of the gel-excised proteins following dialysis in a buffer containing $25 \mathrm{mM}$ Tris, $250 \mathrm{mM}$ glycine and $0.1 \%$ sodium dodecyl sulfate (SDS) and assessment via SDS-polyacrylamide gel electrophoresis (PAGE). Mass spectrometry analysis (On-line Nano-LC MS-MS/MS) of gel-excised recombinant $\operatorname{Tr}$ PTP2 was carried out with the NanoAcquity System (Waters Corporation) coupled to the LTQ Orbitrap Velos nanospray (Thermo-Scientific) using an established protocol (Williamson et al. 2010)

TABLE

Trypanosoma rangeli strains used in this study, their original geographical region and hosts, kDNA group classification according to presence (+) or absence (-) of KP1 minicircle and their respective GenBank accessions for TrPTP2 gene sequences

\begin{tabular}{|c|c|c|c|c|}
\hline Strain & Original host & Geographical origin & KP1 grouping & GenBank \\
\hline SC-58 & Echimys dasythrix & Brazil & - & EU325665 \\
\hline SC-61 & E. dasythrix & Brazil & - & EU325657 \\
\hline SC-76 & Panstrongylus megistus & Brazil & - & EU325660 \\
\hline PIT10 & P. megistus & Brazil & - & EU325656 \\
\hline $\mathrm{C} 23$ & Aotus sp. & Colombia & - & EU325667 \\
\hline 5048 & Homo sapiens & Colombia & - & EU325666 \\
\hline TRE & Not determined & Colombia & - & EU325668 \\
\hline B450 & Rhodnius sp. & Brazil & + & EU325654 \\
\hline $\mathrm{R} 1625$ & Homo sapiens & El Salvador & + & EU325664 \\
\hline H9 & H. sapiens & Honduras & + & EU325662 \\
\hline H14 & H. sapiens & Honduras & + & EU325658 \\
\hline Macias & H. sapiens & Venezuela & + & EU325659 \\
\hline Palma-2 & Rhodnius prolixus & Venezuela & + & EU325663 \\
\hline Choachí & R. prolixus & Colombia & + & EU325653 \\
\hline D3493 & R. prolixus & Colombia & + & EU325655 \\
\hline San Agustín & H. sapiens & Colombia & + & EU325661 \\
\hline 1545 & R. prolixus & Colombia & + & EU325652 \\
\hline
\end{tabular}


with slight modifications. The $\mathrm{m} / \mathrm{z}$ spectrum was processed using Mascot Distiller and Mascot Software (Matrix Science) was employed to perform database searches among $T$. rangeli expressed sequence tags (Grisard et al. 2010) and predicted open reading frames (ORFs).

Monoclonal antibody (mAb) production - mAbs were obtained through immunization of BALB/c mice with TrPTP2 $(50 \mu \mathrm{g})$ according to an established protocol (Mazzarotto et al. 2009). Clones were selected based on exclusive recognition of recombinant and/or native TrPTP2.

Western blotting - Parasite protein extracts were obtained by lysis in an appropriate buffer $(50 \mathrm{mM} \mathrm{NaCl}$, $200 \mathrm{mM}$ Tris- $\mathrm{HCl} \mathrm{pH} \mathrm{8.0,1 \%}$ Triton X-100) at $80^{\circ} \mathrm{C}$. NP40 fractionation was carried out according to a previously described protocol (Woods et al. 1989), with ethylene glycolbis(beta-aminoethyl ether)-N,N,N',N'-tetra acetic acid substituted for ethylene-diamine tetraacetic acid to enable concentration of proteins from the cytoskeletal fraction. After resolution in SDS-PAGE gels, the proteins were transferred to polyvinylidene fluoride (PVDF) membranes (Bio-Rad) in an appropriate buffer $(25 \mathrm{mM}$ Tris, $192 \mathrm{mM}$ glycine, 20\% v/v methanol, $\mathrm{pH}$ 8.3) using a blotting transfer unit (Bio-Rad). After blocking with nonfat milk, the membranes were incubated for 90 min with anti-TrPTP2 or anti- $T c$ PTP2 polyclonal antisera (1:250), anti-PTP2 mAbs (1:2), an anti-His-Tag mAb (Sigma-Aldrich, $1: 12,000)$ or an anti- $\alpha$-tubulin $\mathrm{mAb}(1: 10,000)$, the last of which was used as a loading control.

Immunofluorescence assays - Indirect immunofluorescence assays were carried out as described previously (Stoco et al. 2012) in T. rangeli epimastigotes and trypomastigotes. Anti-PTP2 mAbs (no dilution) and a $\mathrm{mAb}$ directed against the flagellar calcium-binding protein (FCaBP) (1:50) (Schenkman et al. 1991) were used as primary antibodies, with anti-mouse IgG antibodies conjugated to Alexa Fluor 488 or Alexa Fluor 594 (Molecular Probes; diluted 1:1,000) being used as secondary antibodies and 4',6-diamidino-2-phenylindole was added to a final concentration of $1 \mu \mathrm{g} / \mathrm{mL}$. The slides were examined using a Leica TCS SP5 confocal microscope (Leica Microsystems).

Ethics - All procedures involving animals were previously approved by the Ethical Committee on Animal Use of Federal University of Santa Catarina (reference 23080.025618/2009-81).

\section{RESULTS}

The $\operatorname{Tr} P T P 2$ gene has a $987 \mathrm{bp}$ ORF, with a predicted polypeptide product of $\sim 36 \mathrm{kDa}$, which is approximately the same as the predicted size of TcPTP2. The TrPTP2 sequences from all strains were of high quality (Phred $\geq$ 60 ) and are available in the GenBank database under the accessions listed in Table.

The same tree topology was obtained from the phylogenetic analyses using nucleotide sequences regardless of the methodology employed, illustrating that TrPTP2 is useful as a marker for interspecific characterization, but lacks the appropriate bootstrap support for intraspecific characterization (Fig. 1). Interestingly, the KP1(-) strains from Brazil were separated from the Colombian
$\mathrm{KP} 1(-)$ strains, which were grouped with $\mathrm{KP} 1(+)$, indicating a reduced, but clear intraspecific variability between the KP1(-) lineages.

The complete $\operatorname{Tr}$ PTP2 gene sequence was obtained for the $17 \mathrm{~T}$. rangeli strains and nucleotide alignment revealed several substitutions within the coding region, as well as in the 5' and 3' UTRs (data not shown). A comparison of the PTP nucleotide sequences from $T$. rangeli $\mathrm{KP} 1(+)$ with KP1(-) strains showed 23 substitutions. The Colombian $\mathrm{KP} 1(-)$ strains differed from the KP1(+) strains and from the Brazilian KP1(-) strains in three exclusive nucleotide substitutions. However, the identity between the nucleotide sequences from all strains was still close to $99 \%$.

The predicted $\operatorname{Tr}$ PTP2 protein sequence showed a single PTP domain between amino acids 238 and 247, similar to what is observed for the TriTryps PTPs. Comparisons with orthologous sequences from other trypanosomatid species showed high intra and interspecific conservation (Supplementary data). The amino acid sequence identities between $\operatorname{Tr}$ PTP2 and its orthologs are as follows: TcPTP2, 73\%, T. brucei TbPTP1, 59\%, T. congolense, 58\%, T. vivax, $57 \%$, and L. major, $37 \%$.

Southern blot analysis revealed that $\operatorname{Tr} P T P 2$ is present as a single copy gene in the genome of the $T$. rangeli Choachí strain (Fig. 2A, B), which is in agreement with the number of copies of orthologous PTP genes observed in other kinetoplastid species. Northern blot assays showed that $\operatorname{Tr} P T P 2$ encodes a $\sim 1.5 \mathrm{~kb}$ mRNA transcript in both the epimastigote and trypomastigote forms of the T. rangeli Choachí strain (Fig. 2C).

Heterologous expression of both $\operatorname{Tr}$ PTP2 and TcPTP2 using the $\mathrm{pET}-14 \mathrm{~b}$ vector produced a protein of approximately $36 \mathrm{kDa}$ in the insoluble fraction of the lysate, corresponding to the theoretically expected size for these

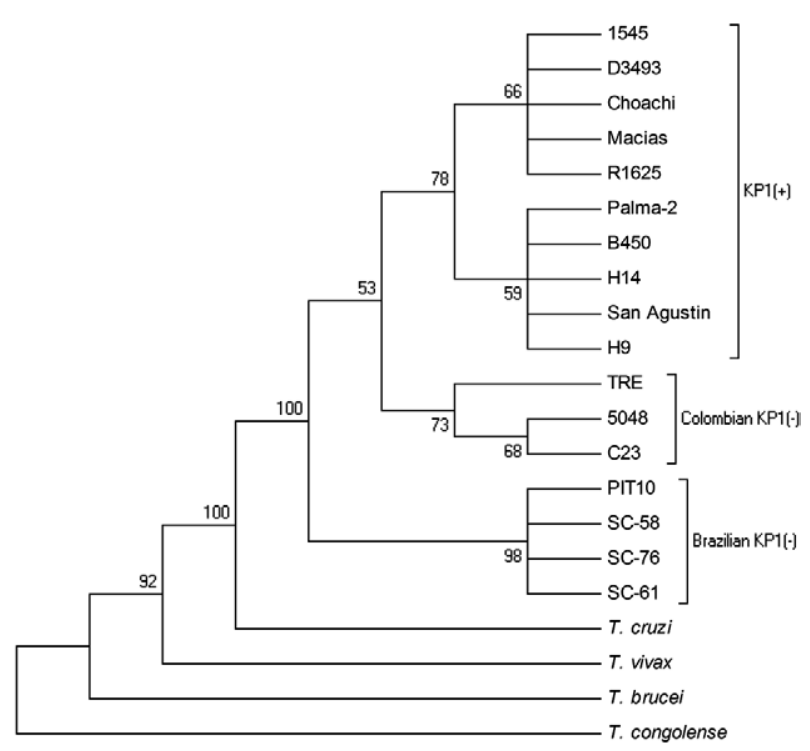

Fig. 1: dendogram analysis based on the Trypanosoma rangeli protein tyrosine phosphatase (TrPTP2) gene. A neighbour-joining $(1,000$ replicates) based-dendogram derived from the analysis of the TrPTP2 gene and its orthologous sequences from distinct trypanosome species. Branches with bootstrap values $<50$ are not shown. 
proteins (data not shown). Mass spectrometry analysis of the recombinant $\operatorname{Tr} \mathrm{PTP} 2$ covered more than $50 \%$ of its peptides and confirmed its identity (data not shown).

Immunization of BALB/c mice with the purified recombinant proteins resulted in the production of anti$\operatorname{Tr}$ PTP2 and anti-TcPTP2 polyclonal antisera. The antiTrPTP2 antiserum recognized a $\sim 65 \mathrm{kDa}$ protein in $T$. rangeli extracts, but not in $T$. cruzi extracts, whereas the anti-TcPTP2 antiserum recognized both TcPTP2 in $T$. cruzi extracts and TrPTP2 in the $T$. rangeli extracts (data not shown). Based on the cross-reactivity obtained using the polyclonal antisera, as well as the identification of a protein that was larger $(\sim 65 \mathrm{kDa})$ than predicted, anti-PTP2 mAbs were produced and selected based on the recognition of both recombinant and native $T r \mathrm{PTP} 2$ in $T$. rangeli extracts.

The anti-PTP2 mAbs showed a strong signal when tested against the recombinant $\operatorname{Tr} \mathrm{PTP} 2$ and specifically recognized the $\sim 65 \mathrm{kDa}$ protein in both epimastigotes

A

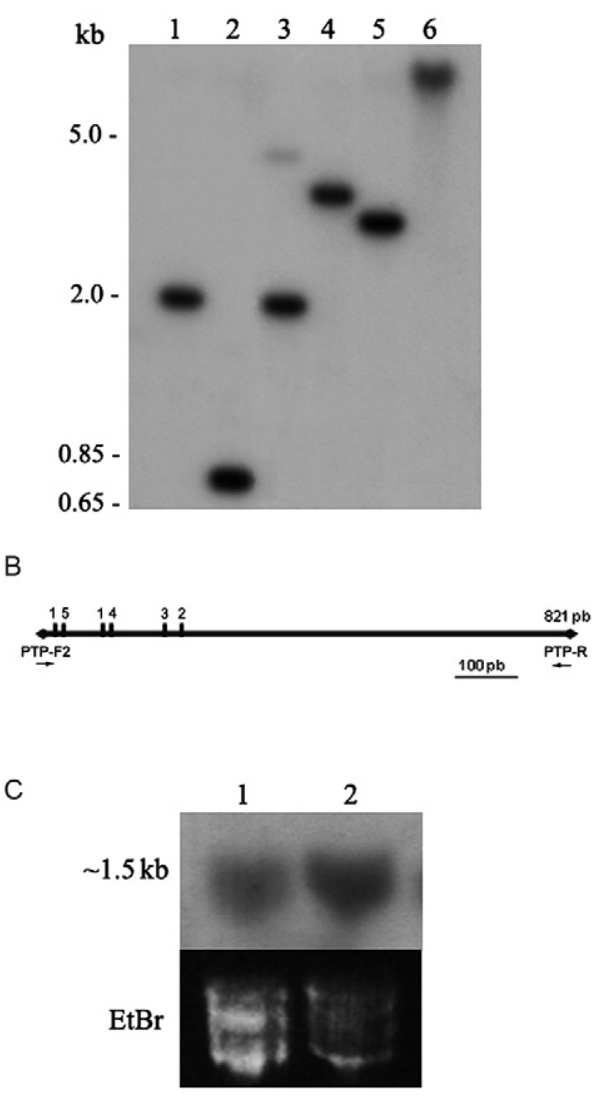

Fig. 2: Trypanosoma rangeli protein tyrosine phosphatase (TrPTP2) is present as a single copy gene and is expressed as a $\sim 1.5 \mathrm{~kb}$ transcript. $\operatorname{Tr} P T P 2$ gene is present as a single copy in the T. rangeli genome as revealed by southern blot analysis (A) using total DNA digested with PstI (1), HinfI (2), BglI (3), BamHI (4), HindIII (5) and non-digested DNA as control (6). B: restriction map of the TrPTP2 gene fragment used as a probe [PstI (1), HinfI (2), BglI (3), BamHI (4), HindIII (5)]; C: $\operatorname{TrPTP} 2$ is expressed as a $\sim 1.5 \mathrm{~Kb}$ transcript as revealed by northern blot analysis using total RNA from epimastigote (1) and trypomastigote (2) forms of Choachí strain. and trypomastigotes from the $T$. rangeli Choachí strain (Fig. 3A). Similar to TbPTP1 in T. brucei, TrPTP2 is detected in the cytoskeletal fraction in T. rangeli (Fig. 3B). Remarkably, mAbs preincubated twice with recombinant TrPTP2 embedded in PVDF membranes could no longer recognize the $\sim 65 \mathrm{kDa}$ protein in $T$. rangeli protein extracts (data not shown). Although TcPTP2 is predicted to be $73 \%$ identical to $\operatorname{Tr}$ PTP2, native TcPTP2 was not detected in T. cruzi by the mAbs generated in this study. This absence of cross-reactivity could be due to the few differences in the amino acid compositions of $\operatorname{Tr} \mathrm{PTP} 2$ and $T c$ PTP2, as shown in the supplementary data.

The observed $\sim 65 \mathrm{kDa}$ protein is almost $30 \mathrm{kDa}$ heavier than the predicted mass of $36 \mathrm{kDa}$ for both TrPTP2 and TcPTP2. This unexpected increase in mass was investigated in several different ways. Although glycosylation sites have been predicted within the amino acid sequence of TrPTP2, analyses using staining with Schiff's reagent did not detect aldehydes in the region corresponding to the $\sim 65 \mathrm{kDa}$ protein in the $T$. rangeli extracts (data not shown), suggesting a lack of significant glycosylation sites within this region. Because dimer formation could also explain the $\sim 30 \mathrm{kDa}$ increase in mass, T. rangeli extracts were resolved via PAGE using $8 \mathrm{M}$ urea as a denaturing agent. This process produced the same $\sim 65 \mathrm{kDa}$ protein (Fig. 3C). Thus, if TrPTP2 forms dimers, they are very stable and resistant to strong denaturing conditions.

Staining with anti-PTP2 $\mathrm{mAbs}$ revealed a strong signal in the $T$. rangeli flagellum in both epimastigotes and trypomastigotes that overlaps with the signal from antiFCaBP mAb, suggesting that TrPTP2 is concentrated in
A

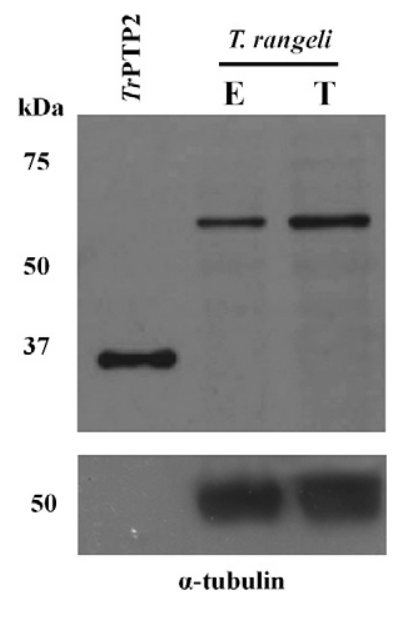

B

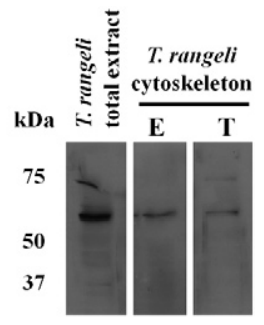

C

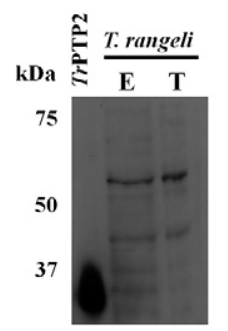

Fig. 3: Trypanosoma rangeli protein tyrosine phosphatase (TrPTP2) expression in $T$. rangeli epimastigotes and trypomastigotes. A: TrPTP2 expression is slightly higher in $T$. rangeli trypomastigotes than epimastigotes as revealed by the anti-PTP2 monoclonal antibodies. Recombinant $\operatorname{Tr}$ PTP2 and $\alpha$-tubulin were used as positive and loading controls, respectively; B: $\operatorname{Tr} \mathrm{PTP} 2$ is detected in the cytoskeletal protein fraction from $T$. rangeli epimastigotes and trypomastigotes; $\mathrm{C}$ : when $T$. rangeli protein extracts are resolved in a gel containing $8 \mathrm{M}$ urea as denaturant $\operatorname{Tr} \mathrm{PTP} 2$ is still detected as a $\sim 65 \mathrm{kDa}$ protein. 
this structure and co-localizes with a flagellar protein (Fig. 4). In epimastigotes, there was also a weak signal detected in the cell body that was not observed in trypomastigotes. In $T$. cruzi, the staining with the mAbs was observed to be subtle and diffuse.

\section{DISCUSSION}

Given that PTPs from pathogenic trypanosomatids, such as T. brucei and T. cruzi, have been reported to play a role in the parasites' in vitro differentiation into infective forms (Szoor et al. 2006) and mammalian host cell infectivity (Gallo et al. 2011), finding a highly similar PTP in a non-virulent species like $T$. rangeli is intriguing.

The $\operatorname{Tr} P T P 2$ gene is present in a single copy in this parasite's genome and encodes a $\sim 1.5 \mathrm{~kb}$ transcript, which is in accordance with a former transcriptome analysis (Grisard et al. 2010). The TrPTP2 gene proved to be a good phylogenetic marker to differentiate T. rangeli from other trypanosomes, but did not exhibit high intraspecificity, despite the variability between the $\mathrm{KP} 1(+)$ and KP1(-) strains, as well as among the KP1(-) strains.

The TrPTP2 transcript is close in size to the T. brucei transcript ( $\sim 1.8 \mathrm{~kb})$ (Szoor et al. 2006), predicting a polypeptide product with a size of approximately $36 \mathrm{kDa}$. This predicted molecular mass is almost identical for both $\operatorname{Tr} \mathrm{PTP} 2$ and $T c \mathrm{PTP} 2$ and is close to the mass reported for the homologous TbPTP1 protein $(\sim 34 \mathrm{kDa})$ (Szoor et al. 2006). In contrast to the recombinant forms of $\operatorname{TrPTP} 2$ and TcPTP2 produced in this study, which were detected in the insoluble fraction of the lysate, Gallo et al. (2011) expressed a recombinant, active $36 \mathrm{kDa}$ T. cruzi PTP in the soluble fraction, which is consistent with the similar sizes of T. rangeli and T. cruzi PTP2 obtained herein.
While the molecular mass of $\sim 65 \mathrm{kDa}$ detected for PTP2 in T. rangeli is similar to a $55-60 \mathrm{kDa} L$. major PTP (Aguirre-Garcia et al. 2006), the increase in mass compared to the predicted $36 \mathrm{kDa}$ protein was unexpected and was investigated in several different ways. Posttranslational modifications, such as glycosylations, have been predicted for $\operatorname{Tr} \mathrm{PTP} 2$ and may dramatically increase protein mass (Sakurai et al. 2008). Formation of dimers could also account for the detection of a protein that was heavier than expected; however, no specific antibody signal near $36 \mathrm{kDa}$ (the expected mass for TrPTP2) was detectable under strong denaturing conditions. We cannot rule out the possibility of covalent oligomerization within the $\operatorname{Tr} \mathrm{PTP} 2$ product itself or with another protein, but the results obtained from urea denaturation suggest that if $\operatorname{Tr} \mathrm{PTP} 2$ forms dimers, they are very stable. A previous study in T. cruzi (D'Orso \& Frasch 2001) detected a difference of $20 \mathrm{kDa}$ between the deduced and obtained mass of the TcUBP-1 protein and parasite transfection was employed to confirm that this increase in mass occurred naturally, possibly due to oligomerization or post-translational modifications. A similar situation might involve $\operatorname{TrPTP} 2$, which could be post-translationally modified through phosphorylation or methylation, both of which are predicted to occur within the TrPTP2 sequence. Additionally, the anomalous electrophoretic migration observed might be due to the estimated high pI of TrPTP2 (8.95) (Chiou \& Wu 1999).

The detection of $\operatorname{Tr} \mathrm{PTP} 2$ in the $T$. rangeli flagellum was a surprising and interesting result obtained in this study. Given that the flagellum in eukaryotic cells is constantly modulated by phosphorylation, it is very likely that dephosphorylation and thus phosphatases play an
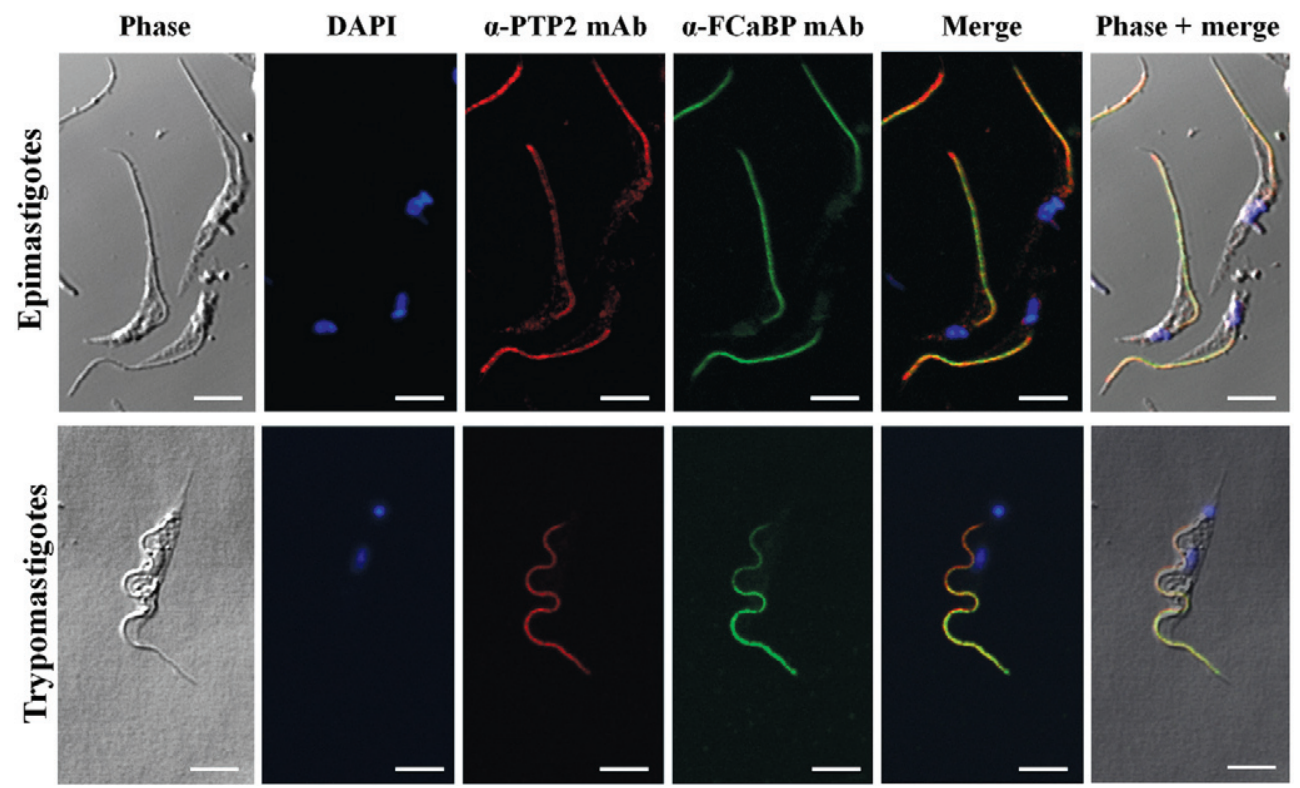

Fig. 4: Trypanosoma rangeli protein tyrosine phosphatase (TrPTP2) is associated with the T. rangeli flagellum. TrPTP2 concentrates in the flagellum and co-localizes with the flagellum calcium-binding protein (FCaBP) in T. rangeli epimastigotes and trypomastigotes as revealed by immunofluorescence assays using anti-PTP2 monoclonal antibodies and anti-FCaBP monoclonal antibodies. Parasites were counter-stained with 4',6-diamidino-2-phenylindole (DAPI). White bars represent $5 \mu \mathrm{m}$. mAb: monoclonal antibody. 
important role in this structure. It has been shown that phosphorylation of axonemal proteins is crucial for regulating flagellar motility, independent of cyclic AMP, in response to an increase in $\mathrm{pH}$ (Nakajima et al. 2005). Interestingly, the in vitro differentiation of $T$. rangeli is successful when the culture $\mathrm{pH}$ is 8.0 , but is drastically impaired when it is 6.0 or 7.0 (Koerich et al. 2002).

Although TbPTP1 is mainly found in the T. brucei cytoskeletal fraction, a specific association with the flagellum was not detected (Szoor et al. 2006). However, a $\mathrm{mAb}$ directed against phosphotyrosine allowed the identification and cytolocalization of tyrosine-phosphorylated proteins in T. brucei (Nett et al. 2009), which were found to be concentrated in the nucleolus region, the flagellum basal body and the flagellum itself. The recognition signal detected throughout the parasite's flagellum disappears in the distal extremity, suggesting that tyrosine-phosphorylated proteins could be directly associated with the axoneme, either adjacent to it or connected to membranous structures near the flagellum (Nett et al. 2009). With the exception of the basal body, the recognition signal for $\operatorname{Tr}$ PTP2 observed in T. rangeli epimastigotes and trypomastigotes precisely follows the same distribution pattern throughout the flagellum.

Given that the T. brucei flagellum contains proteins modulated by specific phosphorylation on tyrosine residues, it is likely that these proteins may also be found in phylogenetically related organisms, such as $T$. rangeli, $T$. cruzi and Leishmania species. Therefore, the presence of $\operatorname{Tr}$ PTP2 in the flagellum is quite intriguing, as concentration of proteins regulated by tyrosine phosphorylation most likely requires tyrosine kinases as well as tyrosine phosphatase enzyme activity.

The mechanisms involved in adhesion to a substrate in T. brucei (Ersfeld \& Gull 2001) T. cruzi (Ferreira et al. 2008) and T. rangeli (Meirelles et al. 2005) require the crucial and active participation of the flagella of these parasites. During metacyclogenesis, the flagellar membrane remains connected to the epithelial surface (Ersfeld $\&$ Gull 2001) representing an important interface between the parasite and its host that is essential for the fulfilment of its biological cycle. The presence of proteins such as PTPs in the flagellum reinforces the role of this structure in both cell differentiation and cell cycle regulation.

\section{ACKNOWLEDGEMENTS}

To Dr. Sergio Schenkman, for the anti-FCaBP antibody, to Dr Claudia Nunes Duarte dos Santos, for providing facilities for mAbs production, and to Dr Hercules Moura, for the MS/MS analysis.

\section{REFERENCES}

Aguirre-Garcia MM, Escalona-Montano AR, Bakalara N, PerezTorres A, Gutierrez-Kobeh L, Becker I 2006. Leishmania major: detection of membrane-bound protein tyrosine phosphatase. Parasitology 132: 641-649.

Andreeva AV, Kutuzov MA 2008. Protozoan protein tyrosine phosphatases. Int J Parasitol 38: 1279-1295.

Brenchley R, Tariq H, McElhinney H, Szoor B, Huxley-Jones J, Stevens R, Matthews K, Tabernero L 2007. The TriTryp phosphatome: analysis of the protein phosphatase catalytic domains. BMC Genomics 8: 434.
Chiou S-H, Wu S-H 1999. Evaluation of commonly used electrophoretic methods for the analysis of proteins and peptides and their application to biotechnology. Anal Chim Acta 383: 47-60.

Cosentino-Gomes D, Russo-Abrahao T, Fonseca-de-Souza AL, Ferreira CR, Galina A, Meyer-Fernandes JR 2009. Modulation of Trypanosoma rangeli ecto-phosphatase activity by hydrogen peroxide. Free Radic Biol Med 47: 152-158.

D’Orso I, Frasch AC 2001. TcUBP-1, a developmentally regulated Urich RNA-binding protein involved in selective mRNA destabilization in trypanosomes. J Biol Chem 276: 34801-34809.

Dick CF, dos-Santos AL, Fonseca-de-Souza AL, Rocha-Ferreira J, Meyer-Fernandes JR 2010. Trypanosoma rangeli: differential expression of ecto-phosphatase activities in response to inorganic phosphate starvation. Exp Parasitol 124: 386-393.

Eger-Mangrich I, de Oliveira MA, Grisard EC, de Souza W, Steindel M 2001. Interaction of Trypanosoma rangeli Tejera, 1920 with different cell lines in vitro. Parasitol Res 87: 505-509.

Ersfeld K, Gull K 2001. Targeting of cytoskeletal proteins to the flagellum of Trypanosoma brucei. J Cell Sci 114: 141-148.

Ferreira LR, Dossin F de M, Ramos TC, Freymuller E, Schenkman S 2008. Active transcription and ultrastructural changes during Trypanosoma cruzi metacyclogenesis. An Acad Bras Cienc 80: 157-166.

Fonseca-de-Souza AL, Dick CF, dos Santos AL, Fonseca FV, MeyerFernandes JR 2009. Trypanosoma rangeli: a possible role for ecto-phosphatase activity on cell proliferation. Exp Parasitol 122: 242-246.

Gallo G, Ramos TC, Tavares F, Rocha AA, Machi E, Schenkman S, Bahia D, Pesquero JB, Wurtele M 2011. Biochemical characterization of a protein tyrosine phosphatase from Trypanosoma cruzi involved in metacyclogenesis and cell invasion. Biochem Biophys Res Commun 408: 427-431.

Gomes SA, Fonseca de Souza AL, Silva BA, Kiffer-Moreira T, Santos-Mallet JR, Santos AL, Meyer-Fernandes JR 2006. Trypanosoma rangeli: differential expression of cell surface polypeptides and ecto-phosphatase activity in short and long epimastigote forms. Exp Parasitol 112: 253-262.

Grisard EC, Stoco PH, Wagner G, Sincero TC, Rotava G, Rodrigues JB, Snoeijer CQ, Koerich LB, Sperandio MM, Bayer-Santos E, Fragoso SP, Goldenberg S, Triana O, Vallejo GA, Tyler KM, Davila AM, Steindel M 2010. Transcriptomic analyses of the avirulent protozoan parasite Trypanosoma rangeli. Mol Biochem Parasitol 174: 18-25.

Koerich LB, Emmanuelle-Machado P, Santos K, Grisard EC, Steindel M 2002. Differentiation of Trypanosoma rangeli: high production of infective trypomastigote forms in vitro. Parasitol Res 88: 21-25.

Mazzarotto GA, Raboni SM, Stella V, Carstensen S, de Noronha L, Levis S, Zanluca C, Zanetti CR, Bordignon J, Duarte dos Santos CN 2009. Production and characterization of monoclonal antibodies against the recombinant nucleoprotein of Araucaria hantavirus. J Virol Methods 162: 96-100.

Meirelles RM, Henriques-Pons A, Soares MJ, Steindel M 2005. Penetration of the salivary glands of Rhodnius domesticus Neiva \& Pinto, 1923 (Hemiptera: Reduviidae) by Trypanosoma rangeli Tejera, 1920 (Protozoa: Kinetoplastida). Parasitol Res 97: 259-269.

Nakajima A, Morita M, Takemura A, Kamimura S, Okuno M 2005. Increase in intracellular $\mathrm{pH}$ induces phosphorylation of axonemal proteins for activation of flagellar motility in starfish sperm. J Exp Biol 208: 4411-4418.

Nett IR, Davidson L, Lamont D, Ferguson MA 2009. Identification and specific localization of tyrosine-phosphorylated proteins in Trypanosoma brucei. Eukaryot Cell 8: 617-626. 
Sakurai T, Sugimoto C, Inoue N 2008. Identification and molecular characterization of a novel stage-specific surface protein of Trypanosoma congolense epimastigotes. Mol Biochem Parasitol 161: 1-11.

Sambrook J, Russell DW 2001. Molecular cloning: a laboratory manual, 3rd ed., Cold Spring Harbor, New York.

Schenkman S, Diaz C, Nussenzweig V 1991. Attachment of Trypanosoma cruzi trypomastigotes to receptors at restricted cell surface domains. Exp Parasitol 72: 76-86.

Stoco PH, Aresi C, Luckemeyer DD, Sperandio MM, Sincero TC, Steindel M, Miletti LC, Grisard EC 2012. Trypanosoma rangeli expresses a beta-galactofuranosyl transferase. Exp Parasitol 130: 246-252.

Szoor B, Ruberto I, Burchmore R, Matthews KR 2010. A novel phosphatase cascade regulates differentiation in Trypanosoma brucei via a glycosomal signaling pathway. Genes Dev 24: 1306-1316.
Szoor B, Wilson J, McElhinney H, Tabernero L, Matthews KR 2006. Protein tyrosine phosphatase TbPTP1: a molecular switch controlling life cycle differentiation in trypanosomes. $J$ Cell Biol 175: 293-303.

Vallejo GA, Guhl F, Carranza JC, Lozano LE, Sanchez JL, Jaramillo JC, Gualtero D, Castaneda N, Silva JC, Steindel M 2002. kDNA markers define two major Trypanosoma rangeli lineages in Latin-America. Acta Trop 81: 77-82.

Williamson YM, Moura H, Schieltz D, Rees J, Woolfitt AR, Pirkle JL, Sampson JS, Tondella ML, Ades E, Carlone G, Barr JR 2010. Mass spectrometric analysis of multiple pertussis toxins and toxoids. J Biomed Biotechnol 2010: e942365.

Woods A, Baines AJ, Gull K 1989. Evidence for a Mr 88.000 glycoprotein with a transmembrane association to a unique flagellum attachment region in Trypanosoma brucei. J Cell Sci 93: 501-508. 


\begin{tabular}{|c|c|c|c|}
\hline \multicolumn{2}{|r|}{ Forward primers (5' to 3') } & \multicolumn{2}{|r|}{ Reverse primers (5' to 3') } \\
\hline \multirow[t]{2}{*}{ PTP-F1 } & \multirow[t]{2}{*}{ CGC TAC CTG ACT TTT CAG CG } & $\begin{array}{l}\text { OligodT- } \\
\text { anchor }\end{array}$ & $\begin{array}{l}\text { GAC CAC GCG TAT CGA TGT CGA C } \\
\text { (T) }{ }_{16} \mathrm{~V}\end{array}$ \\
\hline & & Anchor & GAC CAC GCG TAT CGA TGT CGA CT \\
\hline PTP-F2 & GGG AAG GAA AAG GTG GGG C & PTP-R & CAC CAT TCC AAA (A/G)CG CTG TC \\
\hline TrPTP2 & $\begin{array}{l}\text { CAT ATG GAC ACG CCC AGC ATG GTG } \\
\text { AAG }\end{array}$ & TrPTP2 & $\begin{array}{l}\text { CTC GAG TTA TCT CTG TGG CCT CCT } \\
\text { TCC }\end{array}$ \\
\hline TcPTP2 & $\begin{array}{l}\text { CAT ATG ATG AAT GAT TCG AAC TGC } \\
\text { TTC }\end{array}$ & TcPTP2 & $\begin{array}{l}\frac{\text { CTC GAG TTA TCT CTG TGA ACT TCT }}{\text { TTT TCT }} \\
\end{array}$ \\
\hline
\end{tabular}

List of primers used for amplification and sequencing of Trypanosoma rangeli protein tyrosine phosphatase (TrPTP2) and Trypanosoma cruzi PTP2 (TcPTP2) genes. Sites for NdeI and XhoI restriction enzymes are underlined on forward and reverse primers, respectively.

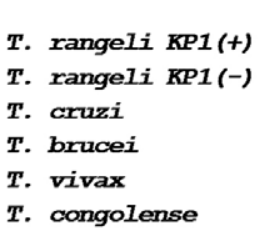

T. rangeli $K P 1(+)$

T. rangeli $\operatorname{KP1}(-)$

T. cruzi

T. brucei

T. vivax

T. congolense

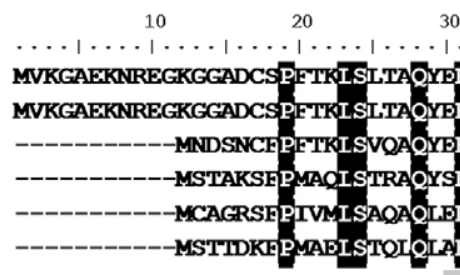

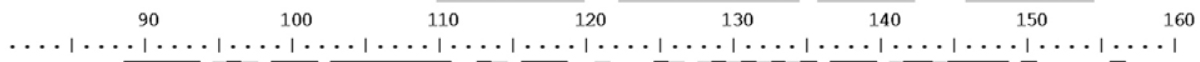

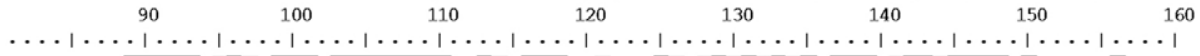

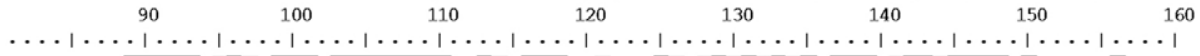

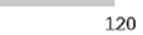
$40 \quad 50$

60

70

80

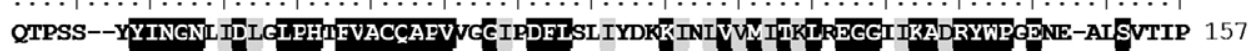

QTPSS--YYINGNLIDLGLPHIFVACCุAFVVGGIPDFLSLIYDKKINIVVVITKLREGGIIKADRYWPGENE-AISVTIP 157

GASTP--YYINGNLIDLDLPHKFVACCCAFVVOGIPDFLAMLYEKKISIVIMVTKLEEGGFVKADRYWPEERG-SGSIAVS 146

GAQPGRYPYINGNLIDIDLPHMFVACCุAFV PCEVPDFLETLSEKKVDIVUMITKLREGGVIKABRYWPEEEEDSLSFPES 149 AKSSVSGCYINGNL IDVGLPHKF VACCAFV PDGIADFLKILCDEIIVVVINITRLEGGVIKADRYWPEEDEQSVSFYDP 149 ENDRGHOCYINGNEVDLDLPHKVVCCAFVPCGMPDLLTLAHGKVNIVINITKLREGGVIKADRYWPEEGEKEISFPLP 149

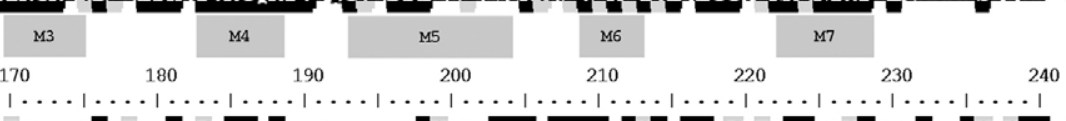

T. rangeli $\mathrm{KP1}(+)$

T. rangeli $\operatorname{KP1}(-)$

T. cruzi

T. brucei

T. vivax

T. congolense

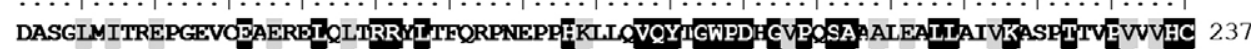

DASGLMITREPGEVOEAERELQLTRR LIFQRPNEPPHKLLVQYIGWPDHGVPSA PALEALLATVKASPTTVEVVHC 237 GNCGLTISEDPGKAYEVEDELKITRRYILQRADEPPHKFTQVQYI GWPDH GIPQSAISLEALLTNVKNSETTVEVVVHC 226 GHDAIKVIRDAEASYEVDABLDIVRR LLVHVPGKPMHRVLOVQY GWPDH GVESA ASFDELLSVIKNCVTISSIIVHC 229 KTGSVRVLRDSEHPYEVDTALEITRR LVIQLPDNSTEOILFVQYI GWPDFGVPRSA SFEALLSIIKSNITDKEVVVHC 229 EGGVVTVRMDPEVPYEVDSTLDITRR LIINMPGKPPELLOVQYIIGWPDHEVPSA AFDALLSVIKOSTTTSEIIIHC 229
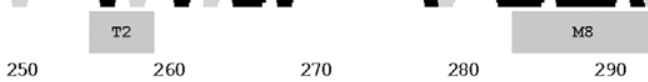

270

300

310

320

T. rangeli $\mathrm{KP1}(+)$

T. rangeli KP1(-)

T. cruzi

T. brucei

T. vivax

T. congolense

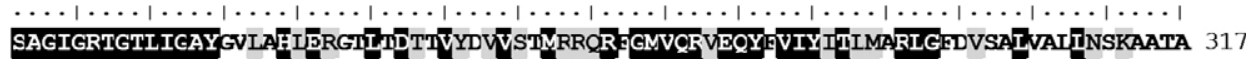

SAGIGRTGTLIGAYGVLAFLERGILIDTTVDVVSTMRRQR GMVCRVEQYFVIYITIMARLGFDVSALVALINSKAATA 317

SAGIGRTGTLIGAYAALTHLERGILIDTTVYDVVSAMRRQR FMVQRMEQYFVIYITIMORLGVDIKALVGLINSRTTAA 306

SAGIGRTGTLIGAYAALL IERGILIDSTVYSIVAAMKQKR GMVCR LEQY VIYMTVLGRLGVDISGLVSTINLKA--- 306

SAGIGRTGTLIGAYAALTHMEQGSLDTKVDIVASMKQQRYMVCRVEQY VIYMTLLTRLGVSVAPLEALIDEKLGAP 309

SAGIGRTGTLIGAYAGITHIERDTLSDTTVYSIVAAMKRKRLGMVQR LEQY VIYITVLSRLGVISGLVSTINIKAGPS 309

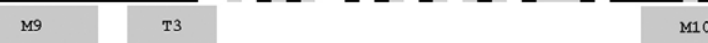

330

$\ldots|\cdots| \cdots \mid \cdots$

T. rangeli KP1(+) ASTAAG--------RRPQR 328

T. rangeli KP1(-) ASTSAG--------RRPQR 328

T. cruzi ASTAAAGGGGEGRKRSQR 325

T. brucei ------------------- 306

T. vivax TPTRGRR------------ 316

T. congolense AA----------------- 311

Deduced amino acid sequence alignment of the Trypanosoma rangeli protein tyrosine phosphatase (TrPTP2) gene with orthologous sequences from different trypanosome species. Motifs related to catalytic activity (M1: binding motive of phospho-Tyr; M8: WPD loop; M9: P-loop catalytic motive; M10: Q-loop), structural motifs inside the catalytic domain (M3-M7), trypanosome-specific motifs inside the catalytic region (T1-T4) and pre-catalytic motifs (PcT1, PcT2) are indicated. Dark background indicates identity and gray background indicates conservation of amino acids. 